\title{
José Martí en Zaragoza
}

Zaragoza produce una impresión primera de desconcierto en el espíritu de Martí. Esta infinita variedad de estilos, desde las más remotas huellas romanas y moriscas hasta el típico estilo regional aragonés, pasando por lo mudéjar, plateresco, renacentista y clurrigueresco, le tienen en constante sorpresa. No se cansa de contemplar tantas reliquias admirables: la mezquita de la Aljafería, los templos del Pilar, la Seo y San Pablo, o de recorrer el viejo Coso, supervivencia de los tiempos de la ciudad amurallada.

Nada semejante vió hasta ahora. iQué nueva emoción ésta de sentir correr su imaginación por las remotas edades mientras curiosamente intenta leer en cada ruina, en cada piedra, la historia milenaria de Cesaraugusta! Zaragoza ibérica, romana, goda, cristiana, musulmana, encierra el más variado muestrario de épocas y de gutstos.

En todo se revela el remoto esplendor, la pasada grandeza. Por los antiguos barrios recorre las tortiosas calles que conducen a la Juderia, o las que serpean cerca de San Pablo o de la Seo. Las,fachadas, los patios milagrosos, las escaleras silenciosas, las anchas galerías con arcos, los escudos en las carcomidas piedras. Como en su contemplación se olvida de todo, muchas veces siente de pronto como si tuviera la impresión de recorrer, solo él, una ciudad desierta que es también una ciudad de en- 
cantamiento. De su olvido de todo y de sí mismo, en sus paseos interminables, con su pequeña libreta donde anota sus impresiones, le sacan con frecuencia las campanadas del reloj de la Torre Nueva, que resuenan en el ambiente purísimo.

El Coso es uno de sus paseos favoritos. Lo sigue a pasos lentos, en la hora del atardecer, desde la casa de los Gigantes hasta el Seminario, deteniéndose frente a la gran cruz que lo corona.

Ante las ruinas del Monasterio de Santa Engracia se sitúa muchas veces. Es sitio de gran recordación para los zaragozanos, que desde allí se defendieron hasta que fué volado por los franceses durante el primer sitio. Su fachada, aún en pie, permite contemplar su pórtico de mármol poblado de innumerables figuras de santos, que permanecían enteros y tranquilos como ignorantes de la catástrofe que los había dejado allí, vigilantes en aquellas ruinas. Con unción contempla estos sitios donde se venera el recuerdo $y$ las hazañas de los héroes, los lugares donde el pueblo aragonés defendió con heroísmo ejemplar su libertad: el Convento de la Encarnación, la Puerta del Carmen -única subsistente de las que cercaban la ciudad, toda agujereada de proyectiles-, el Arrabal, el Arco de Cineja.

Sagrada le parece aquella ciudad, cncarnación de la resistencia heroica, inmortalizada en todas las memorias. Y ahora, él está en su mismo recinto, recorre sus estrechas callejas, sus plazas y paseos, mientras resuenan en su pecho los ecos de la leyenda. Y su imaginación le transporta a la isla distante, quemada de sol, donde otros hombres, hermanos suyos, pelean también por su libertad, y como aquellos aragoneses, se abrazan a la mituerte antes de caer prisioneros de sus enemigos.

Un hondo gemido se le escapa del pecho: es la queja íntima que a cada momento le atormenta recordándole que él debe estar allá, entre los que cumplen con su deber. Pero mientrás así se recrimina, otra voz más íntima y’ más fuerte 'sale de su misma alma a consolarle: su esfuerzo no es de este momento; 
ya llegará su hora, y entonces sí será digno de su patria.

A los pocos días todo en Zaragoza le es familiar. $\mathrm{Y}$ no sólo siente una entrañable devoción por la milagrosa ciudad de los cien templos, tan llena de sorpresas para la inquieta imaginación; también sus alrededores le ofrecen un ambiente de serenidad y de paz íntima, de que tanto necesita después de sus dos años de intensa vida madrileña. Va al canal de Pignatelli, pasea por la ribera, o se aleja en silencio o acompañado de Fermín (I) rumbo al. Monte Torrero, para regresar cuando ya comienza a oscurecer. Por el camino se detienen a contemplar los árboles; la corriente del Ebro, los campanarios de la ciudad que asoman sobre el verde de lö campos, la cúpula del Pilar, las tapias de los huertos por sobre las cuales las ramas se desgajan o se muestran las flores de la primavera. Estos paseos le traen al recuerdo sus meses lejanos del Hanábana, cuando en tardes como éstas se alejaba por los campos, andando cerca del río, y era su mayor goce ese puro contacto con la naturaleza. $Y$ otro recuerdo mucho más cercano le pasa támbién por la memoria: el de sus pocas semanas en Isla de Pinos, cuando la idea de la deportación le bailaba en la mente como única salvación para su vida. Fermin recoge en silencio sus evocaciones; en las que a menudo aparece la figura amàda de Mendive (2) o el recuerdo quemante de sus padres $y$ de sus hermanitas. ¿Ningún recuerdo tan doloroso como éste!

Al llegar a Zaragoza, los amigos han tomado un modesto hospedaje provisional. Al día siguiente, 23 de mayo, ya hacen acto de presencia en el vetusto edificio al final de la calle del Sepulcro, cerca de la plaza de San Nicolás. Martí presenta un escrito en el que hace valer sus derechos y pide admisión a examen.

Después es preciso buscar hospedaje más adecuado para la vida que se proponen hacer. No es empresa difícil, con el deseo 
de servirles que en todos encuentran cuando saben que son cubanos que dejan la corte para instalarse en su ciudad.

En una casa de huéspedes de la calle de la Manifestación se les acoge. Allí se acomodan a sus anchas. El patrón $y$ sus bellas hijas, a quienes todos conocen por "las paticas verdes", rivalizan en hacerles amable la estancia. Don Félix Sanz comprende el gusto con que Martí se entera de las historias de la ciudad y de las anécdotas que el pueblo conserva vivas; y da rienda suelta. a sus relatos cada vez que la oportunidad le depara momento propicio. Otras večs lo acompaña para mostrarle los rincones históricos que él conoce, y es tanto el ardor bélico que pone en sus palabras, que Martí le llama el patrón valiente. Pero la gran sorpresa de Zaragoza se la proporciona un negro cubano, limpiabotas del Arco de Cinejas. A Simón lo había deportado Lersundi, en su primera remesa a Fernando Poo, por ñáñigo y asesino. En Zaragoza halló vida decorosa y para Martí y Fermín es catusa de regocijo encontrarlo en su misma casa de huéspedes. Simón representa algo muy real de su Cuba distante, que a cada momento surge en el acento peculiar de sus palabras:

Cumplidos los trámites necesarios, llega a la Universidad de Zaragoza el informe favorable de don Pedro Alcántara García, Secretario General de la Universidad Central de Madrid, y. ya en junio realiza Martí los exámenes de todas las asignaturas trasladadas, aprobándolas.

Su afán de concluir rápidamente es grande. Necesita realizar un enorme esfuerzo por lo mismo que ahora puede decirse que está pesando sobre Fermín, y no quiere ser sino lo menos gravoso posible. Además, tienc un anhelo que le complaceria mucho satisfacer: realizar los estudios de filosofía y letras - su verdadera vocación. $\mathrm{Y}$ sólo venciendo con rapidez extraordinaria las materias que le quedan podrá probar fortuna.

El 29 de agosto formula solicitud de examen por enseñanza libre de ocho asignaturas de la facultad de derecho, de las cua- 
les examina y aprueba hasta seis en el mes de septiembre, quedándole pendientes Procedimientos judiciales y Práctica forcnse.

Al mismo tiempo que realiza estos estudios prepara los del bachillerato, cuyo título necesita poseer antes de optar al grado de derecho. Ya don Mariano (3) le ha enviado certificación de sus estudios en el Instituto de la Habana "con las notas calificativas de su aplicación y aprovechamiento".

También la vida espiritual de Zaragoza produce un dulce bienestar en el alma de Martí. Recibido en todas partes con agasajos, invitado por las familias de sus profesores, que llegan a tratarlo como amigo más que como discípulo, le rinde y le conmucve sentirse en este círculo de corazones amigos. La universidad es como su casa grande, donde pasa muchas horas del dia cn estudio, en consulta de libros en la excelente biblioteca; o en conversaciones amenísimas con profesores para quicnes resaltan las grandes disposiciones innatas de Martí y el acento personal con que interpreta y trata todos los asuntos, bien politicos, bien de arte o de literatura.

En este convivio con hombres afines se afianza más aún su idea de que sólo la libertad puede producir la felicidad del hombre. ¿Será algún día posible en su isla libre un semejante contacto entre hombres de esta categoria espiritual?

Esta vetusta casa de Zaragoza, donde sus triunfos son motivo de regocijo para condiscípulos y profesores, afirma poderosamente en su alma el pleno valor de las cósas del espiritu. $Y$ las cosas del espíritu no pueden vivir sino en un ambiente de libertad.

Llega Martí a tanta compenetración con el alma de la ciudad, que mejor que en las salas de la biblioteca o en el saloncito de la casa de huéspedes, prefiere pasar las tardes estudiando en el pequeño y solitario paseo al costado de la Iglesia del Pilar; o en algún banco a orillas del Ebro herboso. Algunos dias se le ve alli con aire de honda abstracción, escribiendo febrit- 
mente en el cuaderno que apoya en la rodilla. Es su drama conccbido en Madrid y entonces apenas esbozado, que ahora concluye en el sosiego de Zaragoza. Cuando le ha leido a Fermin las escenas ya concluidas el amigo. queda maravillado de tanto concepto filosófico y de tanta belleza literaria; pero. lo que más le impresiona es el gran temple moral de su compañero. Ciertamente que la austeridad de Martí es conmovedora; casi está por parecerle excesiva.

Las mañanas de los días festivos y de aquellos en que no tiene clases o no tiene examen próximo, las consagra a la $\mathrm{Al}$ jafería, que le atrae singularmente $y$ donde según la leyenda zaragozana, se guarda el primer oro llevado de Cuba por los conquistadores. Cuando no, a contemplar las ricas colecciones de famosos tapices conservados en los templos del Pilar, la Seo o. San Pablo, que recuerdan el auge de la tapicería zaragozana en el siglo XVI; o a visitar en las catacumbas, debajo de Santa Engracia, los innumerables Santos Mártires de Zaragoza. Por las tardes prefiere visitar los museos en busca principalmente de las huellas del pintor rebelde y luminoso que para Martí encarna un mensaje doble, de hombre libre y de artista. Goya, que pone luces en la pintura de su tiempo, que la limpia de sombras y terciopelos, de guerreros y magistrados, saturándola de vida popular y de claridades, salió de aquella ticrra. Ha podido admirar sus retratos de Fernando VII o del Duque de San Carlos, y de aquel gran amigo hasta la muerte, Martín Zapater. También halla muebles de su época y cartas escritas por su mano al amigo entrañable. En su cartera de niño hay unas cabezas con lápiz rojo a lo Rafael, y se conservan tambiéu sus cucuruchos de obispo y sus cabezas sin ojos. Y le impresiona para toda la vida su modo arrebatado y firme de pintar. Goya es ya uno de sus maestros "y de los pocos pintores padres". En los templos, cartujas y capillas dejó también sus huellas el pintor sincero que por serlo pareció nuevo. De Goya es el fresco de la Alegoría de la Divinidad o de la Gloria que contempla en el coreto 
de Nuestra Señora del Pilar, la Visita de la Virgen a Santa Isatbel, que decora la capilla de la Casa de Sobradiel, las diez composiciones de Asuntos Misticos que cubren los muros de la Cartuja de Aula Dei, cerca de Zaragoza.

El estudio del pintor Gonzalvo le acoge con frecuencia. Es ligar en que transcurren horas deliciosas, cambiando ideas sobre la gran pintura española o la pintura de la escuela aragonesa, cuando no contemplando obras del maestro, como su admirable Interior de la Catedral de Toledo. Pero quizá nada le guste tanto como estar en silencio largos ratos, mientras el pincel va creando su mundo de formas y colores.

Lugares de gran camaradería lo son el Atenco Científico y Literario de la calle del Coso, el Casino Artístico, donde se coṇservan tablas, retablos, lienzos, obras maravillosas que datan de los siglos XIV, XV y XVI. La redacción del "Diario de Avisos", donde encuentra siempre un grupo de amigos que ya tienen alta estimación por su pluma. En el diario provinciano queda algín trabajo suyo que transparenta la feliz inspiración de este momento dichoso.

Y no faltan, además, las invitaciones a pasar un día de campo en la torre de algún amigo, como la del notario López Bernuez, donde admira su muy valiosa colección de monedas y cerámicas.

El crítico de arte nace en Madrid; pero es en Zaragoza donde adquiere conciencia clara de sus propios sentimientos artísticos. Los juícios que van naciéndole a cada paso frente a monumentos y obras de arte los recoge en su libreta de notas, donde se mezclan con reflexiones filosóficas, juicios literarios $y$ versos de amor.

Las fiestas y regocijos populares le impresionan intensamente, por esa singular concurrencia de seriedad y ceremonia de irrespetuosidad y socarronería, que caracteriza a los hombres del pueblo.

Una de las más típicas, la procesión de gigantes y cabezudos, 
grotesca personificación de tipos populares o históricos, se celebra la víspera de la cercmoniosa gran fiesta del Pilar. Esta fiesta no tiene precedente en parte alguna. Más de $35^{\circ}$ faroles ricamente adornados, representando el Santísimo Rosario con todos sus misterios, y cuyos distintos tamaños tienen relación con su simbolismo, forman la comitiva en esta procesión del Rosario monumental. La ciudad resplandece y el pueblo fervoroso se enciende en delirio místico.

En los días de Pasión, los templos rivalizan en el sobrio decorado donde los maravillosos tapices sirven de severo marco a los Sagrarios. Pueblo valiente e ingenuo, la rudeza exterior ofrece a menudo la sorpresa de una bondad interna, vivida sencilla y naturalmente.

La afición a las representaciones, ya bien arraigada, no deja tampoco de cultivarse. Por el contrario, un abono al palco número trece del Teatro Principal -el palco al que nadie se abonaba-, dice bien la frecuencia de su asistencia. $\mathrm{Y}$ allí, como en todos los demás sitios, la amistad es la mejor dádiva para sus corazones. En la larga lista de sus amigos están Zabala y Dronda, Ariño, Penen, Peiro, Daina, Arpal, Villarrolla, Ordaz, Zapata, Luzón. ..

Junto a todo esto, el cariño de una mujer de la que se siente profundamente enamorado. El encuentro sucede en casa de uno de sus profesores que más lo estiman y donde Martí es visita frecuente. Ella se emociona con el timbre suave y firme de su voz, con la finura de sus modales, con la belleza de sus palabras, con el fuego de su entusiasmo. Las palabras galantes que él le dice le parece que nunca antes las había ódo iguales. iQué raro dón tiene este muchacho que todos se encantan oyéndolo hablar, y hasta el niño de la casa se sienta muy tranquilo en su butaca cuando llega el estudiante cubanof. $Y$ dice que le gutstan mucho los cuentos que le oye! La amistad que aquí surge entre los jóvenes se convierte muy pronto en impetuoso amor: Es tan bella $y$ tan delicada Blanca de Montalvo, que a 
él le parece como la primera flor de la primavera de su vida. $Y$ tiene tanto deseo de ser amado, anhela tanto un poco de comprensión y de cariño, que se siente feliz como nunca.

Aunquie muy descreído de los milagros de la República después de haber conocido de cerca la actuación de los hombres que fueron'sus inspiradores, no deja por eso Martí de seguir al tanto del proceso político, motivo de largas conversaciones y discusiones en la tertulia del "Diario de Avisos", en el Ateneo $y$ en otros sitios frecuentados por él. La actuación de Castelar le parece la más culpable de todas. Ya desde el funesto zo de septiembre de 1873 podia asegurarse que la Repüblica había muerto, y que Cistelar había sido su verdugo, como sostenía el integro don Francisco Pi y Margall. El pensamiento del gran mantenedor del federalismo coincidia con el de Martí: "Voluble como poeta y vanidoso como mujer, se dejó desde el primer instante seducir por los que, llenándole de falso incienso, conspiraban sin descanso por la restauración de la Monarquía". Y como Pi y Margall, créa èl también que si no había sido un traidor era por lo menos un hombre sin fe y sin convicciones.

Consecuencia de la política vacilante y torpe, de transacciones y entrega continua a los elementos adictos a la restauración, fué la caída de la República en la madrugada del 3 de enero de 1874 , cuando el general Pavía, gobernador militar, obliga al gobierno a resignar sus poderes, lo que hace exclamar a Pi y Margall: "Puede asegurarse que sucumbió no a manos de Pavia, sino a manos de Castelar".

Contra este golpe surgen protestas y agitaciones republicanas en. muchas ciudades de España. Algunas resultaron verdaderamente sangrientas, y ètre éstas se cuenta la de Zaragoza.

Sus cuatro batallones de nilicias: republicanas se niegan a reconocer al nuevo gobierno y el pueblo los secunda en la protesta. Se distribuyen armas, se levantan barricadas en las calles 
y se apoderan de muchos edificios desde los cuales consideran defendido el movimiento.

Las tropas gubernamentales, mandadas por el general Burgos, jefe militar del distrito, rompen fuego a la una de la tarde. Una batería de diez cañones Krupp enfila sus proyectiles contra los edificios siutados en las esquinas del Arco de Cinejas y el Coso, desde los cuales resisten los zaragozanos. Más reñido aún resulta el combate en el Mercado, en la Puerta del Angel y en el Cuartel de la Magdalena, lugares todos contra los que las columnas de ataque hacen fuego incesantemente.

En las primeras horas de la noche el movimiento queda sofocado. Hay, entre muertos y heridos, algunos centenares por ambas partes. $Y$, como en su despacho dice el capitán general de Aragón, la lucha "fué breve y rápida; pero ruda y terrible".

Fermín y Marti han permanecido en su hospedaje durante aquellas horas de lucha. Bien sabian ellos que era un gesto heroico pero inútil, y además, que la República que por momentos sucumbia apenas merecía el nombre de tal. Para Cuba había sido fratricida. Nada les obligaba a defenderla; ningún deber se lo reclamaba.

Del hospedaje sólo había faltado el negro Simón, que jurito a los valientes atrincherados en el Arco de Cineja peleó hasta el último momento. Cuando ya la noche había entrado y se aplacaban las descargas de fusilería, él, después de muchas horas de rudo pelear $\mathrm{y}$ de ver caer a su lado a muchos valientes republicanos, trató de ponerse a salvo. Pudo conseguirlo con un hábil rodeo, y ya amanecía cuando llegó a la puerta del hospedaje de la calle de la Manifestación. Verlo entrar produce a los cubanos una vivísima alegría. $\mathrm{Y}$ al preguntarle Martí qué hay de nuevo, el cubano negro - "hombre de armas y de frases"- contéstó:

- Niño, hay un frío que se hielan las palabras.

Esta misma mañana, ya apaciguada la ciudad, Fermín y Martí recorren los sitios desde los cuales se ha hecho la heroica 
defensa, encontrando por todas partes charcos de sangre ennegrecida junto a las barricadas.

Aunque Martí no ha tomado participación activa en esta jornada, no por eso deja de dolerle la terrible derrota que sufren los hombres liberales y valientes de la ciudad bien amada. El siente su dolor como suyo, y es tuno más que la tiranía le proporciona.

$\mathrm{Y}$ porque saben su modo de pensar y lo hondo de su cariño por Zaragoza defensora de la libertad, a él le piden que sea quien hable en el acto público que las butenas gentes organizan para aliviar la situación tristísima de las viudas y los huérfanos. Se lo ha pedido también quien no puede ser desairada - Blanca de Montalvo, que es ya dueña de su corazón. Hay, además, otro motivo para que sea Martí el que dirija la palabra en esa ocasión: su carácter de extranjero asegura cierta neutralidad en estos momentos en que aún los ánimos están excitados, y en que la autoridad dominante se halla recelosa del carácter del acto.

Martí se siente hondamente complacido con que se le brinde esta única oportunidad de expresar su cariño por Zaragoza, por su hospitalidad, por su concepto de la dignidad verdadera, la dignidad del hombre que quiere ser libre por sobre todas las cosas y muere si es preciso por sus ideas. Su discurso es un amplio cuadro de sus propias aspiraciones, de sus mismos anhelos, $y$ un himno a los hombres para quienes el sacrificio es una forma de cumplimiento del deber. $Y$ aunque bien claro dice que la República no ha sido ni con mucho el sueño de los mejores republicanos, sino una caricatura, una deslealtad a la misma idea que la inspiró, entona un canto a la República verdadera, a la República del respeto y del decoro de todos los hombres, que es por la que él trabaja.

No sólo pronuncia el discurso de la noche, sino que son suyos los versos que Leopoldo Burón, el famoso actor y amigo de Madrid, ha leido con maestría y entusiasmo. 
Así es doblemente aclamado, como orador y como poeta, este insurrecto de Cuba que se ha ganado la admiración y el cariño de cuanto vale en la muy vetusta Zaragoza.

Es ya irremediable la pérdida de la República. Al golpe del General Pavía sigue una vergonzosa sumisión y un rápido movimiento hacia la restauración borbónica. Todos los síntomas le hacen presumir que no terminará el año sin que el absolutismo monárquico impere nuevamente en España. Aunque ciertamente nada en favor de Cuba le debe a la República, le punza el dolor de su fracaso. Sobre todo siente como una pesadumbre la vueltá de un régimen bajo el cual se le härá dificil sù estancia en España. Adivina medidas reaccionarias que harán irrespirable el ambiente.

A terminar rápidamente sus estudios se consagra por entero. $Y$ no sólo tiene empeño en concluir sus dos carreras, práctica la una, la otra ideal, sino que es necesario' prepararse también para las pruebas del bachillerato. Será un esfuerzo muy grande si, como piensa y quiere, ha de terminar antes de que finalice el año, en la convocatoria de septiembre.

Además, no son pocas las cartas apremiantes que le llegan de doña Leonor; (4) pintándole la angustiosa situación de la familia. Don Mariano ha pasado largas temporadas sin trabajo y sufre cada vez más de sus ataques de asma. El retrato que la recibido últimamente le aumenta la inquietud al contemplarlo tan consumido y demacrado. Ya no le encuentra aquella fortaleza y energía de unos años atrás: la adversa fortuna y los sufrimientos morales van haciendo su obra. Gran dolor para él esta conciencia de que es la dirección misma de su existencia la que causa tales estragos en la vida de los suyos. Ahora él necesita vivir para ellos, serles útil, recompensarles de tantos sinsabores. A Cuba no pódrá volver; será preciso hacer una vida nueva en cualquier parte, tal vez en México, que es tierra hospitalaria donde podrá hallar trabajo para sostenerlos a todos y vivir para ellos: Se lo ha escrito ya a su madre, que ha 
palpitado de alegría ante esa posibilidad de verlo' y abrazarlo; de reconstruir su vida de familia quizá.: Don Mariano se ha mostradó escéptico: de las repúblicas de América sólo una le parece digna de admiración: la del Norte. Las demás no son para tomarse en cuenta. Sin embargo, recuerda que en México tíene algunos amigos que allá han encontrado medios de vida. Y Y poco a poco le va ganando la idea de venderlo todo $\mathrm{y}$ marcharse con los suyos.

$\therefore \quad$ Los ejercicios de grado de bachiller se han señalado : para los días 25 y:27 de junio en el Instituto de Zaragoza, $\ddot{y}$ en ellos obtiene calificación de aprobado en èl primero y en el segiundo de sobresaliente. Unos días antes ha logrado sacar las dos asignaturas de la facultad de derecho quedadas del curso anterior, y ya sólo le falta verificar el ejercicio de grado. Lo realiza el día 30 de junio y obtiene, con calificación de aprobado, el título de Licenciado en derecho civil y canónico.

De esta suerte queda expedito para dedicarse por entero a las materias de filosofía y letras que tanto le apasionan. Julio $y$ agosto son meses de entrega total al estudio, y el $3^{I}$ de este mes solicita matrícula por enseñanza libre para todás las asignaturas de la carrera, con excepción de aquellas que por pertenecer al año preparatorio de la facultad de derecho tiene ya aprobadás. I en septiembre examina, una tras otra, la larga serie de asignaturas: Lengua griega, Literatura clásica y griega, Geografia histórica, Metafísica y Estudios críticos sobre autores griegos, alcanzando algunos sobresalientes.

Pero le ha faltado exäminar dos materias para completar los estudios: Lengua hèbrea e Historia de España. Y cómo el período de examen ha terminado el día $3^{\circ}$, necesita recurrir a la autoridad del Rector para alcanzar la especial concesión. Alega en su escrito que en la creencia de que no se formaria tribunal de dichas materias, se retiró en las últimas horas del día $3^{\circ}$ en la seguridad de que por to àvanzado de la hora se formaría posteriormente. El Dr. Ballarin, rector accidental, acepta 
las razones de Martí y dispone su examen, que verifica en los primeros días de octubre. El 20 pide señalamiento de tribunal y día para optar el grado de licenciado de la facultad de filosofía y letras, y el 24 se constituye el tribunal designado, que integran los profesores don Martín Villar, don Andrés Caballero y don Antonio Hernández. De las tres bolas extraidas de la urna elige Martí la número trece cuyo tema es "La oratoria política y forense entre los romanos, Cicerón como su más alta expresión: los discursos examinados con arreglo a sus obras de retórica". Cuando al cabo de tres horas de incomunicación desarrolla el tema ante el tribunal, subyuga a cuantos presencian aquellos ejercicios, por la brillantez y originalidad de sus ideas y la magnificencia de su discurso. Aun los jueces le hacen observaciones durante media hora, dando a conocer en sus respuestas el vigor de su mente y el dóminio de su palabra. La calificación de sobresaliente corona este extraordinario y brillante esfuerzo que denota bien el alcance de su inteligencia y lo firme de su vocación.

Con sus títulos por único patrimonio, sin medios aún de realizar el viaje, sale Martí de Zaragoza. Una triste despedida de todo lo que le ha sido tan grato y acogedor, y de la mujer amada, le ensombrece aquellos momentos. iQuién sabe si no volverá a verla! También le oprime el corazón pensar en lo que el destino le deparará en la nueva tierra americana donde ya le esperan todos los suyos. Por suerte a su lado está Fermín, consuelo y protección en su desamparo.

Su pobreza no le permitió sacar sus títulos. Sólo lleva con. sigo certificaciones de sus estudios. En Madrid los legaliza el Director General de Institución Pública, don José Moreno Nieto, y después el Ministerio de Estado. El encargado del Constulado de México en la Corte, don Juan R. Castellanos, auténtica las firmas el 16 de diciembre.

En Madrid se demoran unos días más. Meses antes, a prin- 
cipios de junio, hizo un viaje rápido a la corte y en vano trató de encontrar "trabajo intelectual, de versión, cualquier trabajo que le produjese lo suficiente para el pago de su matrícula en la facultad de filosofía y letras, que espontáneamente amaba y que con insaciable aliento de pobre deseaba para si". El editor a quien entonces se dirigió no pudo darle trabajo, pero él ha unido a su título de licenciado en derecho el de licenciado en filosofía.

$Y$ ahora ha de comenzar lejos de España el ejercicio de su carrera, y si antes no pudo lograr trabajo, ahora le hace una rara proposición: en cambio de libros que necesita le ofrece "los frutos ligeros de una inteligencia incipiente que confia en producirlos un día". Y como muestra le envía un trabajo escrito -en buena parte al volver de verlo cuando le formuló su primera proposición. Ese artículo, muchos otros, todos los que considere necesarios si son estimables, está dispuesto a darle a cambio de los libros que han de ayudarle en su carrera.

Los libros que tanto le interesaban - -el Diccionario de Escriche, los Comentarios de Gutiérrez, y como complemento más grato, las dos obras filosóficas de Azcárate-, ¿llegan a sus manos en aquella breve estancia de Madrid?. Lo probable es que su rara proposición aparezca aún más rara al editor desconocido. "Artículos de buena voluntad por libros de buena ciencia. Trabajo ofrecido en cambio de bases de trabajo; no hay en ello, sin embargo, rareza alguna".-Eso pensaba Martí.

No quiere Fermín que salga de Europa sin visitar alguna de las grandes ciudades. $\mathrm{Y}$ se dirigen a Paris.

Con los últimos días del otoño llegan a París. Ya la ciudad se apresta a volver a su existencia mágica. Pero aún tienen tiempo de recorrer los boulevares, los jardines del Luxemburgo, de hacer una excursión a Versailles, de contemplar el dorado paisaje y el volar de las hojas llevadas por los vientos rudos, antes de que los primeros copos de nieve empiecen a caer. 
Es una gran suerte para los amigos llegar en este momento en que todo comienza a resurgir al soplo de los primeros vientos invernales. Todas las actividades de la mente y del corazón renacen en estos días, $\mathrm{y}$ es como un privilegio que las circunstancias les deparan.

$\mathrm{La}$ animación se hace creciente: los periódicos registran lla lucha de los candidatos a la Academia, los votos posibles con que cuentan, los méritos que los adornan, las circunstancias que pueden influir en su elección.' $Y$ recogen los nuevos debates en la Cámara, verdaderas batallas parlamentarias en las que resplandece, entre exaltaciones y delirios, el gran amor con que por distintos rumbos cada diputado quiere servir a Francia.

No pasa día sin nuevos libros en los escaparates, libros escritos durante los meses de veraneo "a la sombra de los naranjos de Italia, de los tilos alemanes, de las casas blancas de Bougival, de los álamos severos de Argenteuil". 'Los teatros rivaliżan en ofrecer sus nuevos dramas, nacidos también en los días apacibles del veraneo provinciano, que es la fuente de la renovadora fecundidad. La dorada sala de la Gran Opera reluce de público solemne, la Sorbona abre sus puertas a las sabias disertaciones, y en los cafés de los boulevares se reanudan las pláticas y fulgura el ingenio y la alegría. Es la primavera del espíritu que llega con todos sus nuevos brotes. Martí y Fermín quieren verlo $\mathrm{y}$ vivirlo todo, $\mathrm{y}$ asisten a las representaciones de Sara Bernhardt; que deja impresión perdurable en sus espíritus.

Las salas de los museos se animan también con los estudiantes que llegan de todas pártes y emprenden alegres la copia de famosos cuadros. Martí ya aprovecha su tiempo recorriendo las vastas salas del Louvre o del Luxemburgo, bebiéndose a sorbos rápidos la gran pintura de Francia. Los desnudos le atraen singularmente, $y$ se detiene ante esas carnes tersas y esas formas opulentas de Gérome, ante La Baigneuse provocativa de Perrault o las mujeres esbeltas, pero sin espíritu en su carne, de Beaumont.' Lefèbvre le impresiona especialmente con sus mu- 
jeres de formas llenas y exquisitas, con la pureza inimitable del seductor contorno. Para Martí, Lefèbvre es sin duda el maes: tro del desnudo. En su libreta anota sus impresiones: no le basta llevarse la luz y el color en su recuerdo, quiere apurar y reducir a fórmulas lo que esas obras maestras dejan en su espíritu: La Lune de Miel, un delicado paisaje de Leconte du Nours, le hace pensar en la afortunada compenetración de los efectos del alma y la expresión de la Naturaleza.

En España hizo estudios de francés. Es idioma que le gusta naturalmente y para el que descubre tener una verdadera facilidad. Su ansia de saber lo llevó a leer las obras de los pensadores y poetas de. Francia en su lengua original antes de que la dominara. Pero así pudo avanzar mucho en poco tiempo, y ahora lo comprueba con honda complacencia, en sus conversaciones con artistas y escritores. Especialmente ha intimado con un poeta de inteligencia valerosa y carácter sereno y firme, con el que deja sellada una excelente amistad: Auguste Vacquerie. $Y$ ha sido el propio Vacquerie quien ha querido que Martí traduzca una hermosa canción suya, y por primera vez en su vida lo ha hecho, en estos mismos días de su estancia en París.

Vacquerie le ha proporcionado uno de los momentos de mar yor felicidad de su vida : lo lleva a la presencia de Víctor Hugo, y el viejo y gran poeta lo recibe con paternal afecto. Martí lo ve como a padre, o como cosa suya, y siente desbordársele la admiración por la venerable figura.

Ya el gran poeta de Francia ha tenido oportunidad de decir al mundo su simpatia por la causa cubana, por "la noble y valerosa Cuba" y para Martí esa expresión de simpatía que el poeta ha reiterado es motivo de profunda gratitud que personalmente ha querido expreșar al maestro. "He levantado ya la voz por ella, y de seguro que la levantaré de nuevo". - decía Víctor Hugo:

$Y$ como Vacquerie muestra al poeta la traducción que Martí acaba de hacerle, Víctor Hugo pone en sus manos un pequeño 
libro recién publicado - Mes fils- al tiempo que le expresa su deseo de verlo traducido. Y Martí vive un instante en contento, tiene una alegría pueril cuando sabe que ha de traducir este libro grave $y$ amado del poeta.

Ya próximo a partir, pasa una tarde en el cementerio de Père Lachaise. El muchacho romántico y'apasionado que deja tras de sí sut primer amor, va a la tumba de los enamorados, la tumba simbólica llena de poéticas sugestiones en que descansan Abelardo y Eloísa:

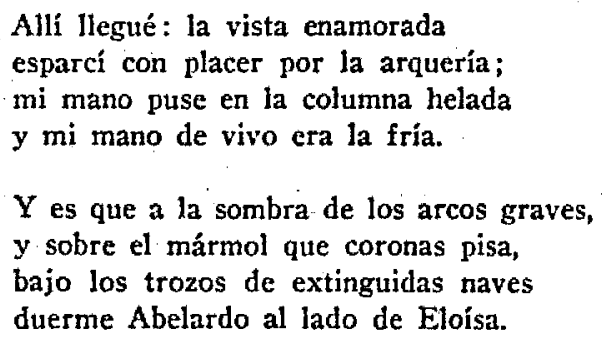

Quiere Fermin que Marti visite algunas otras ciudades de Europa antes de embarcar para México. Dejan París y a mediados de enero están en Southampton, donde Martí, que ha llegado enfermo, embarcará rumbo a México. Con un abrazo se despiden los dos amigos en este puerto sombrío. En el barco de emigrantes le espera una penosa travesía. Pero lleva consigo las páginas grandilocuentes del desterrado de Guernesey, que le han de hacer compañía y dar alientos para stus mismos empeños.

Bien ha pensado Fermín que Martí hará su viaje como emigrante ansioso de llevar un poco más de dinero a su familia. Su previsión era justa; pero él se ha adelantado, abonando la diferencia del pasaje de primera. Comienzan sus horas de angustia a bordo, en un inmundo sitio en que se hacinan centenares de hombres; $y$ un hedor sofocante hace imposible la respiración. Con un plato sucio y una cuchara en la mano está delante de un caldero que le hace recordar el rancho del presidio 
en la Habana. Y ctuando anonadado busca en los rostros que le rodean un destello de inteligencia o una lágrima de dolor, una voz le saca de sus reflexiones:

-Mr. Martí.

Un momento, y cuando ya instalado en un cómodo camarote de primera, se ve libre de aquel lugar de pesadilla donde hacer vivir al hombre es una inhumanidad, no puede contener las lágrimas pensando en su amigo, en su hermano, que sigue acompañándolo en este viaje hacia nuevas y desconocidas realidades.

En Nueva York es preciso cambiar de barco, rumbo a México. En sólo unas horas de demora, apenas puede ver los edificios altísimos que se reflejan casi en las aguas de la bahia. Cuatro días después entran en el puerto de la Habana, también por unas horas. Sin los suyos, sin Mendive, sin Fermín, esta tierra amada sobre la que pesa una odiosa esclavitud no es sino un gran infierno regido por hombres dominados por los más innobles apetitos y las más inhumanas pasiones. Acodado en la barandilla se sume en dolorosisimas meditaciones, repasando todo el vertiginoso acontecer de su vida. Cuatro años antes salió proscripto y ahora lo es más que nunca, ahora que todo es una dispersión. Será preciso reunir con amor todas las partes para alcanzar el todo. Pero ha de llegar un día...

Si hubiera comunicado a alguien su pensamiento de este instante, una sonrisa incrédula sería la respuesta.

El día 8 de febrero de 1875 fondea en Veracruz, a las $6 y$ media de la tarde, el vapor americano "City of Mérida" del que desembarca Martí, para seguir viaje a la capital en el ferrocarril de Veracruz. Al llegar a la estación de Buenavista divisa a don Mariano que le esperaba tendiéndole los brazos. Sin pronunciar una palabra, se confunden en un fuerte e interminable abrazo.

Fér.rx Lizaso. 
(1) - - Dr, Fermín Valdés Dóminguez, amigo de Marti desde 'ja infancia y. quien lo socortrió económicamente durante el exilio de ambos en Espa: ña. Era hombre rico, y le fué muy leal a Martí toda la vida.

(2).-Rafael Maria de Mendive, poeta y patriota cubano.

(3).-Mariano Martí, padre del poeta apóstol.

(4)--Leonor Pérez de Martí, madre de Martí. 